\title{
CAXUMBA E INFECÇÃO AGUDA DO SISTEMA NERVOSO CENTRAL (SNC)
}

\author{
Sydney Schmidt
}

\section{RESUMO}

Dentre 916 casos de "Meningite Asséptica" internados no Hospital de Doenças Tropicais de Goiânia no período de 1982 - 1993, o vírus da caxumba foi o mais provável agente etiológico de 157 $(17,14 \%)$ casos, pois havia concomitância de parotidite ou história recente de contágio intradomiciliar. Foram levantados dados sobre a idade dos pacientes, o tempo de permanência hospitalar, o tempo de duração da doença e em que dia da caxumba surgiram os primeiros sinais do acometimento do S.N.C.. Os exames de rotina do L.C.R. foram solicitados e, no sangue a amilasemia. $O$ tipo de acometimento nervoso, a concomitância de pancreatite e os anos e meses de maiores e menores incidências são citados. $\mathrm{O}$ autor enfatiza que o acometimento cerebral não deve ser considerado uma complicaçào e sim forma clínica da parotidite epidêmica do mesmo modo que a pancreatite e a orquite.

UNITERMOS: Meningite Asséptica. Caxumba. Formas Clínicas.

\section{INTRODUÇÃO}

A Caxumba, doença de aparente benignidade, pode complicar-se no seu curso com surdez aguda, obstrução do conduto de Stenon, crises convulsivas, distúrbios hidroeletrolíticos graves, paralisia facial, miocardite e nefrite intersticial, dentre outras ocorrências mais comuns $(2,3,4,7,9,10,11,14,21)$ ou deixar seqüelas importantes como hidrocefalia por obstrução do aqueduto de Sílvio, atrofia testicular, ginecomastia masculina, subfertilidade, fibroelastose cardíaca e a discutível lesão irreversível das células beta das Ilhotas de Langerhans ${ }^{(6,8,12,13,15,16,17,18,19,20,22)}$.

A literatura citada também considera complicações a meningite asséptica, a pancreatite e a orquite. No caso das infecções neurológicas, admite-se que a complicação decorra da ação sobre o S.N.C. de peptídeos tóxicos, por analogia com o 
SCHMIDT,S. Caxumba e Infecção Aguda do Sistema Nervoso Central (SNC). Rev.Pat.Trop.,23 ( 2 ):205213.jul./dez. 1994 fator depressivo do miocárdio (F.D.M.) liberados pelo pâncreas nos casos de choque
(1).

Este trabalho objetiva estimular esforços no sentido de se estabelecer rotina laboratorial para o diagnóstico específico das causas mais comuns das infecções agudas do S.N.C.; despertar a atenção para melhor avaliação de possíveis sequelas e, principalmente, colocar em discussão o que deve ser considerado complicação, seqüela e forma clínica da Caxumba.

\section{MATERIAIS E MÉTODOS}

A partir da análise retrospectiva dos prontuários de pacientes com " meningites assépticas " internados no Hospital de Doenças Tropicais de Goiânia (H.D.T.) entre 1982 e 1993, foram identificados aqueles com acometimento concomitante das parótidas; destes colheu-se a história clínica, os dados epidemiológicos, a evolução da doença, os resultados dos exames liquóricos (citometria, citologia, aspecto, glicorraquia e proteinorraquia) e do sangue (amilasemia). Anotou-se ainda, os dias de internaçào, de doença antes do aparecimento dos primeiros sinais do comprometimento neurológico, a idade e o sexo dos pacientes, o mês e ano das internaçб̃es. De todos os dados foram calculados a média, a mediana, a moda, o desvio e o erro padrão.

\section{RESULTADOS}

Dentre 916 casos de " meningite asséptica", 157 (17,14\%) tinham Caxumba: 139 apresentavam sinais de irritação meníngea, de hipertensão endocraniana e febre; 15 com os sinais acima descritos mais comprometimento do sensório e 3 com perda total do sensóric e hipotonia, sendo que um destes apresentou crises convulsivas. Em algum momento ca doença todos se queixaram de cefaléia.

D. 156 casos, $42(26,92 \%)$ apresentaram dor abdominal e vômitos esporádico:, 10 (6,41\%) dores abdominais em barra, vômitos incoercíveis e amilasemia elevada, 1: $(9,61 \%)$ apenas dor abdominal e $89(57,05 \%)$ não relataram qualquer queixa digestiva. Não se colheram informações de um paciente que foi a óbito.

As faixas etárias de 5 a 9 anos e 10 a 14 anos contribuiram com 100 casos (63,69\%). A relação entre o sexo masculino e o feminino foi de 1,75:1, observando-se que a partirdos 15 anos houve tendência a se igualarem. TABELA 1 .

Mcrecem destaque três casos: $O$ primeiro, uma criança de 9 anos, masculino, apresentou fuadro clínico considerado muito grave, rotulado de meningoencefalite póscaxumba, extrema fraqueza muscular, dor abdominal intensa, obnubilado, febril e
SCHMIDT,S. Caxumba e Infecção Aguda do Sistema Nervoso Central (SNC). Rev.Pat.Trop.,23 ( 2 ):205213,jul./dez.1994

desidratado. No momento da internação a citometria era de $470 \mathrm{cel} / \mathrm{mm}^{3}$, proteinorraquia de 44,0mg\%, glicorraquia $61,3 \mathrm{mg} \%$, amilasemia de 1675,0 Un/d1.Teve alta no nono dia de internação após enérgica correção do equilíbrio ácidobásico e medicação sintomárica; $O$ segundo caso rotulado de meningite era uma criança de 12 anos, do sexo feminino, que chegou ao hospital acompanhada de sua mãe e de mais três irmãos com caxumba. Estava lúcida, vomitava muito e queixava-se de fortes dores abdominais.

TABELA 1. Caxumba associada com infecção do S.N.C. Ocorrência de internaçð̃es no H.D.T. de Goiania Distribuição por faixa etária, sexo, cura e óbito no período 1982 a 1993.

\begin{tabular}{|c|c|c|c|c|c|}
\hline \multirow[b]{3}{*}{ IDADES } & \multicolumn{4}{|c|}{ SEXO } & \multirow{3}{*}{ TOTAL } \\
\hline & \multicolumn{2}{|c|}{ MASCULINO } & \multicolumn{2}{|c|}{ FEMININO } & \\
\hline & CURA & ÓBITO & CURA & ÓBITO & \\
\hline 1 ano & - & - & - & - & - \\
\hline 1-4 anos & 10 & - & 04 & - & 14 \\
\hline 5-9 anos & 44 & - & 20 & - & 64 \\
\hline $10-14$ anos & 25 & - & 11 & - & 36 \\
\hline 15-19 anos & 06 & 01 & 07 & - & 14 \\
\hline 20-29 anos & 12 & - & 10 & - & 22 \\
\hline $30 e^{+}$ & 03 & - & 04 & - & 07 \\
\hline TOTAL & 100 & 01 & 56 & - & 157 \\
\hline
\end{tabular}

Não apresentava caxumba que só veio a exteriorizar-se dois dias após sua internação. A citometria era de $1280 \mathrm{cel} / \mathrm{mm} 3$, a glicorraquia de $36,5 \mathrm{mg} \%$ e a proteinorraquia de $98,0 \mathrm{mg} \%$. A amilase dosada era de $2016,0 \mathrm{Un} / \mathrm{d} 1$. Com medicação sintomática e hidratação o quadro cedeu no segundo dia e no quarto de internação teve alta com discreta rigidez de nuca; $\mathrm{O}$ terceiro caso, o único óbito registrado ocorreu em jovem de 18 anos que deu entrada no HDT com quadro compatível de encefalite e história de Caxumba há 18 dias. No momento da internação. o L.C.R. apresentava-se com citometria de $61 \mathrm{cel} / \mathrm{mm} 3$, glicorraquia de $77,0 \mathrm{mg} \%$, proteinorraquia de 234,0 $\mathrm{mg} \%$ e no sangue a amilase dosada de $240,0 \mathrm{Un} / \mathrm{d} 1$. A necrópsia mostrou encéfalo com 
SCHMIIDT,S. Caxumba e Infecção Aguda do Sistema Nervoso Central (SNC). Rev.Pat.Trop.,23 ( 2 ):205213,jul./dez.1994

áreas hemorrágicas, algumas alterações degenerativas, infiltração local do tipo nomonuclear, perivascular sem evidência de inclusões virais.

A média de idades dos pacientes foi de 12,25 $\pm 8,10$ com mínima de 3 e máxima de 40 anos. $O$ tempo de permanência hospitalar variou de 2 a 8 dias $(\bar{x}+4,67$ $\pm 1,61)$. Os sinais de comprometimento do S.N.C. surgiram entre o segundo e o décimo primeiro dias $(\overline{\mathrm{x}}=5,18 \pm 2,11)$; em 3 pacientes surgiram antes do aparecimento da caxumba.

Em todos os casos, o aspecto do L.C.R. era claro, límpido e transparente; a contagem celular diferencial mostrava predominância de células nononucleares sobre as polimorfonucleares, estas não ultrapassando a $25 \%$ do total. A citometria variou entre 21 e $1692 \mathrm{cel} / \mathrm{mm} 3(\bar{x}=427,19 \pm 380,61)$; a glicorraquia de $24,1 \quad 136,9 \mathrm{mg} \%$ $(\bar{x}=54,76 \pm 19,05)$; a proteinorraquia de 10,5 a $234,0 \mathrm{mg} \%(\bar{x}=59.96 \pm 36,85) . \mathrm{A}$ bacterioscopia foi negativa em todos os casos e em 28 pacientes a amilase dosada variou de 82,2 a $2016,0 \mathrm{Un} / \mathrm{d} 1(\overline{\mathrm{x}}=568,10 \pm 549,99)$ sendo o valor normal pelo método utilizado de 60 a $120 \mathrm{Un} / \mathrm{d} 1$. Em quatro pacientes a amilase apresentou-se nos limites da normalidade. TABELA 2.

TABELA 2. Caxumba associada com infecção do S.N.C. Ocorrência de internaçð̃es no H.D.T. de Goiânia. Dados clínicos e laboratoriais dos pacientes internados no período de 1982 a 1993.

\begin{tabular}{llllrrrrr}
\hline & $\begin{array}{l}\text { Dias } \\
\text { de } \\
\text { inter. }\end{array}$ & $\begin{array}{l}\text { Celul. } \\
\text { (cel/mm3) }\end{array}$ & Glicor & Proteinor & $\begin{array}{l}\text { Amila- } \\
\text { semia }\end{array}$ & $\begin{array}{l}\text { Dias / } \\
\text { Caxumba }\end{array}$ & $\begin{array}{l}\text { Acom. } \\
\text { SNC-dias } \\
\text { apos } \\
\text { caxumba }\end{array}$ & $\begin{array}{l}\text { Idade / } \\
\text { pacientes }\end{array}$ \\
& & & & & & & & \\
MÉDIA & 4,67 & 427,20 & 54,77 & 59,96 & 568,10 & 6,21 & 5,18 & 12,25 \\
ERRO- & 0,15 & 41,04 & 2,14 & 4,23 & 103,94 & 0,32 & 0,30 & 0,65 \\
PADR20 & & & & & & & & \\
MEDIANA & 5,00 & 280,00 & 52,00 & 53,50 & 374,00 & 6,00 & 5,00 & 10,00 \\
MODA & 5,00 & 90,00 & 52,00 & 32,00 & - & 5,00 & 4,00 & 6,00 \\
$\begin{array}{l}\text { DESVI0- } \\
\text { PADR20 }\end{array}$ & 1,61 & 380,62 & 19,05 & 36,86 & 550,00 & 2,40 & 2,11 & 8,10 \\
AMOS'RAS & 108 & 86 & 79 & 76 & 28 & 56 & 51 & 157 \\
\hline
\end{tabular}

SCHMIDT,S. Caxumba e Infecção Aguda do Sistema Nervoso Central (SNC). Rev.Pat.Trop. 23 (2) 209 213,jul./dez.1994

No período de estudo, os meses de outubro e novembro concorreram com maior número de internaçð̃es: $49(31,21 \%)$ e os de fevereiro e março com o menor: 9 (5,73\%). TABELA 3.

Dentre os 916 casos de " meningite asséptica" em apenas 34 foram isolados os agentes etiológicos (3 M.tuberculosis e 31 C.neoformans).

TABELA 3. Caxumba associada com infecção do S.N.C. Ocorrência de internaç̃̃es no H.D.T. de Goiânia. distribuição anual e mensal no periodo de 1982 a 1993.

\begin{tabular}{lccccccccccccc}
\hline & 1982 & 1983 & 1984 & 1985 & 1986 & 1987 & 1988 & 1989 & 1990 & 1991 & 1992 & 1993 & TOTAL \\
\hline JANEIRO & 5 & 1 & 1 & 0 & 2 & 3 & 0 & 0 & 1 & 0 & 2 & 2 & 17 \\
FEVEREIRO & 0 & 1 & 0 & 0 & 1 & 2 & 0 & 1 & 0 & 0 & 1 & 0 & 06 \\
MARÇO & 0 & 0 & 0 & 0 & 0 & 0 & 1 & 0 & 2 & 0 & 0 & 0 & 03 \\
ABRIL & 0 & 1 & 0 & 0 & 0 & 5 & 0 & 0 & 1 & 1 & 1 & 1 & 10 \\
MAIO & 0 & 1 & 0 & 2 & 4 & 1 & 1 & 0 & 2 & 0 & 0 & 3 & 14 \\
JUNHO & 0 & 1 & 0 & 2 & 2 & 0 & 1 & 0 & 3 & 0 & 1 & 1 & 11 \\
JULO & 1 & 0 & 0 & 0 & 2 & 0 & 0 & 1 & 3 & 2 & 0 & 1 & 10 \\
AGOSTO & 1 & 0 & 0 & 1 & 4 & 0 & 0 & 1 & 4 & 0 & 0 & 0 & 11 \\
SETEMBRO & 1 & 3 & 0 & 2 & 3 & 0 & 0 & 0 & 3 & 0 & 0 & 1 & 13 \\
OUTUBRO & 1 & 1 & 1 & 2 & 6 & 2 & 0 & 1 & 1 & 1 & 4 & 4 & 24 \\
NOVEMBRO & 1 & 0 & 1 & 4 & 5 & 1 & 1 & 2 & 4 & 0 & 0 & 6 & 25 \\
DEZEMBRO & 1 & 1 & 1 & 5 & 0 & 1 & 0 & 1 & 2 & 0 & 1 & 0 & 13 \\
TOTAL & 11 & 10 & 4 & 18 & 29 & 15 & 4 & 7 & 26 & 4 & 10 & 19 & 157 \\
\hline
\end{tabular}

\section{DISCUSSÕES E CONCLUSÕES}

À Caxumba, atribui-se complicações que nada mais são do que acometimentos simultâneos de outros órgãos pois, as parótidas não são alvo exclusivo do vírus da Caxumba.

Complicações são intercorrências na fase aguda da doença, não obrigatoriamente causadas pela ação direta do vírus, geralmente benignas, fugases mas que, eventualmente podem ser causas de óbitos ${ }^{(4)}$. Podem estar relacionadas com 
SCHMIDT,S. Caxumba e Infecção Aguda do Sistema Nervoso Central (SNC). Rev.Pat.Trop.,23 ( 2 ):205213.jul./dez.11994

reaçðes imunológicas ${ }^{(2)}$ ou à liberação de peptídeos tóxicos pelo pâncreas quando lesado pelo vírus ${ }^{(1)}$.

Seqüelas são lesões definitivas em conseqüência da ação viral, não detectadas na fase aguda da doença, incapacitantes, algumas responsáveis por neoplasias malignas como as dos testículos e tumores da mama masculina ${ }^{(8,18)}$.

A pancreatite, as infecções agudas do S.N.C. e a orquite não devem ser consideradas complicações da Caxumba e sim formas clínicas da doença. Pode-se aceitar a meningite asséptica como complicações, se for admitido que, sua ocorrência é devida à ação viral sobre o pâncreas, mas restaria explicar porquê o maior número de afecções do S.N.C. na concomitância da Caxumba acontece sem quaisquer sinais indicativos de lesão pancreática.

Deve-se considerar como formas clínicas da parotidite epidêmica: 1 Caxumba; 2 - Caxumba com acometimento simultâneo de outros órgãos e 3 acometimento de outros órgãos sem Caxumba.

Nenhuma intercorrência foi observada durante a fase aguda dos casos aqui apresentados, exceto o desvio do equilíbrio ácido-básico decorrente de vômitos incoercíveis e desidratação; a forma clínica predominante foi a da Caxumba com acometimento do S.N.C., salvo em 7 que além da Caxumba e da meningite asséptica também apresentaram sinais clínicos e laboratoriais evidentes de pancreatite. Vômitos incoercíveis foram observados em 10 pacientes que apresentaram quadro de desidratação, mas somente 7 quadro de pancreatite pois, além do quadro clínico apresentaram amilasemia superior a 700,0 Un/d1. Todos estes casos reverteram à normalidade do desvio ácido-básico pela reposição de soluções eletrolíticas e medicação sintomática. Os vômitos provavelmente foram consequiência do comprometimento pancreático pois, quando se trata de vômitos causados por hipertensão endocraniana, geralmente eles desaparecem após a punção lombar, mesmo que a retiræda de líquor seja de pequenas quantidades.

$\mathrm{Na}$ Caxumba, a sonolência dificilmente está ausente, mesmo quando o compromeimento aparente é apenas das parótidas, fato que sugere afecção encefálica principalmente, porque, quando puncionados o L.C.R. desses pacientes revela citometria slevada.

Pıde-se concluir que os dados clínicos laboratoriais e epidemiológicos da casuística ipresentada, foram suficientes para o diagnóstico das infeç̧ões agudas do S.N.C. pelø vírus da Caxumba, quando da existência de concomitância. Contudo não se pode afirnar que seja exato o número de 157 casos dentre os 916 de meningite asséptica internados no período de estudo. Para tal, seria necessário estabelecer-se rotina laboatorial para o diagnóstico específico dos agentes etiológicos mais prováveis das infecçeses assépticas do S.N.C. pois as técnicas imunológicas disponíveis são bastante acssíveis.
SCHMIDT,S. Caxumba e Infecção Aguda do Sistema Nervoso Central (SNC). Rev.Pat.Trop.,23 ( 2 ):205213,jul./dez.1994

Amilasemia elevada, vômitos e dor abdominal não selam o diagnóstico de pancreatite porque a amilase pode estar muito elevada apenas pelo comprometimento inflamatório das parótidas, os vômitos seriam conseqüência da hipertensão endocraniana e as queixas de dores abdominais à palpação, demasiado subjetivas em pacientes desidratados e obnubilados.

É de grande importância a reidratação nos pacientes com vômitos incoercíveis e, quase sempre, com comprometimento do sensório; muitos casos aprioristicamente rotulados de encefalites ou meningoencefalites são restabelecidos com este procedimento.

\section{SUMMARY}

\section{Mumps and infections of Central Nervous System (C.N.S.)}

Among 916 cases of aseptic meningitis admited into the " Hospital de Doenças Tropicais of Goiânia between 1982 and 1993, mumps vírus was the probably implicated agent in $157(17,14 \%)$ cases based on epidemiological and clinical (parotitis) evidence.

A restropective analysis of patient's age, duration of hospitalization and of disease, time between Central Nervous System (C.N.S.) manifestation and begining of the disease was compilated. Cerebral spine fluid analysis and amylase titulation in blood were also compilated. Concomitance of clinical pancreatitis and temporal distribuition of the cases are shown. The author emphasizes the C.N.S. manifestations are not a complication of mumps: they are a clinical feature like pancreatitis and orchitis.

KEYWORDS: Aseptic meningitis, parotitis, Clinical features. Epidemic Parotitis, Sequelae.

\section{REFERÊNCIAS BIBLIOGRÁFICAS}

01. BECKER, Y. Complications after mumps result from damage to the pancreas. Med.Hipothesis, 18 (3) 187-192, 1985. 
SCHMIDT,S.. Caxumba e Infeç̧ão Aguda do Sistema Nervoso Central (SNC). Rev.Pat.Trop.,23 ( 2 ):205213,jul./dez.1'1994

02. BITNUN,S.; RAKOVER, Y. \& ROSEN, G. Acute bilateral deafness complicating mumps. J. Latyngol. Gtol. 110 (8): 943-945, 1986.

03. BLAND, J.O.W. Mumps complicated by myocarditis, meningoencephalitis and pancreatitis. New engl.J.Med. 240: 417, 1949.

04. CHAUDARY, S. \& JASKI, B.E. Fulminant mumps myocarditis. Ann. Intern. Med. 110 (7): 569-579, 1989.

05. FINE, P.E.; ADELSTEIN, A.M.; SNOWMAN, J.; CLARKSON, J.A. \& EVANS, S.M. Long term effects of exposure to viral infection in utero. Br.Med. J. (Cl.res.), 290 (6467): 509-511, Abstract, 1985.

06. HYOTY,H.; LEINIKKI,P.;REUNANEN,A.; KONEN,J.; SURCEL, H.M. \& SILVA, A. Mumps infection in the etiology of type L (insulin-dependent) diabetes. Diabetes Res. 9 (3): 111-116, 1988.

07. LEVITT, L.P.; RUCH, T.A. \& KINDE, S.W. Central Nervous System mumps. A review of 64 cases. Neurology (minneap.) 20: 829-834, 1970.

08. MABUCHI, K.; BROSS, D.S. \& KESSLER, I.I. Risk factor for male breast cancer. J. Natal. Cancer Inst., 74 (2): 371-275, 1985.

09. NOMURA,Y.; HADARA.,T \& SUGIURA,A. Sudden deafness and assynptomatic mumps. Acta otolaryngol. Supp.(Stockh), 456: 9-11, 1988.

10. OZKUTLU,S; SOYLEMZOGLU,AS.; KALE,G. \& KARAASLAN,E. Fatal mumps myocarditis. Jpn.Heart J. 30 (1): 109-114.

11. PARAIV,D. \& BOULLOCHE,J. Crises epileptiques multifocales post-ourliennes. Neurophydiol. Clin., 18 (2). 187-191. 1988.

12. RATZNANN, K.P. Does mumps infections play in the etilogy and pathogenesis of insılin dependent Diabetes mellitus? Med.Intern.24 (4): 245-252.1986.

13. RATZUANN, K.P.; JAHR,H. \& RITHER,K.V. Complement-mediate cytotonic effects of islet cell surface antibodies in non diabetic subjects with antecedent mumps infection and diabetic risk. Exp.Clin.Endocrinol.,91 (2): 17618:.1988.
SCHMIDT,S. Caxumba e Infeç̧ão Aguda do Sistema Nervoso Central (SNC). Rev.Pat.Trop.,23 ( 2 ):205213.jul./dez.1994

14. ROBERTSON,J.F. \& AZMY,A.A. Facial paralysis in acute paroditis, Z.Kinderchir, 42 (5): 312. 1987.

15. ROTILIO,A.; SOlAR.G.; DOLLO,C.; ORI,E. \& CARTERI,A. Aqueducta stenosis following mumps viral infection. Case report. Ital.J.Neurol.Science, (2): 237-239.1985.

16. SCHULTZ,B.; MICHAELIS,D.; HILDMANN,W.; WITT,S; HEMKE,B \& RAJASANOWSKI,I. Islet cell surface antibody (ICSA) in subject with a previous mumps infection. A prospective study over a 4 yer perios. Exp. Clin. Endocrinol.,90 (1):62-70.1987.

17. SHAKHOV,E.V. \& KRUPIN,V.N. The clinical statistical characteristics of testicular generative function in male subfertility following mumps. Virol.Nefrol. (Mask),12:46-50.1990.

18. SWERDLOW,A.J., HUTTLY,S.R. \& SMITH,P.G. Testicular cancer and antecedent diseases. Br.J.cancer,55 (1): 97-103.1987.

19. TIMMONS,G.S. \& JOHNSON,K.P. Acqueductal stenosis and hydrocephalus after mumps encephalytis. N.Engl. J. Med.183:1505-1507.1979.

20. VOSBURGH,J.B.; DIEHL,A.M.; LIV,C.; LAVRER,R.M. \& FABIYI,A Relationship of mumps to endocardial fibroelastosis. Complement fination, hemaglutination-inhibition and skin test for mumps in clildren with and withalt endocardial fibroelastosis. Am.J.His.Clild,109:69-73.1965.

21. WARD, S. C.; WISELKA, M. J. \& NICHOSON,K.G. Still's diseases and muocarditis associated with recent mumps infection. Postgrad.Med. J.; 64 (755): 693-5.1988.

22. WITTE,C.L.; SCHANZER,B. Pancreatitis due to mumps. Jama, 203: 1068. 1968. 